\title{
GAMING FOR PEACE: GENDER AWARENESS TRAINING AND THE POLISH MILITARY
}

\author{
Anne HOLOHAN, PhD \\ aholohan@tcd.ie \\ Associate Professor, GAP Principal Investigator and Coordinator \\ Trinity College Dublin, Ireland \\ Justyna PYZ, PhD \\ pyzj@tcd.ie \\ Research Fellow, GAP Project Manager \\ Trinity College Dublin, Ireland \\ Kamila TROCHOWSKA, PhD \\ k.trochowska@akademia.mil.pl \\ Assistant Professor \\ War Studies University
}

The GAP project has received funding from the European Union's Horizon 2020 research and innovation programme under grant agreement no. 700670 .

This article only reflects the views of the author(s), and the EU is not responsible for how the information may be used.

\begin{abstract}
Despite regulatory and legal changes, women are persistently underrepresented in military organisations on peacekeeping missions. This article argues that part of the reason for this can be found in persistent stereotypical ideas about gender roles, and looks at the attitudes and experience of Polish military personnel who have been deployed on peacekeeping missions as evidence of this. However, witnessing other militaries stance on gender, where such stereotypes are still there, but not as entrenched, can cause personnel to contextualise if not question their own organisation's stance on gender. Sixteen Polish military peacekeepers were interviewed in-depth about their experiences on peacekeeping missions as part of a European H2020 project, Gaming for Peace (GAP). The interviews


were used to build scenarios for a digital role-playing game to develop soft skills among peacekeeping personnel, and these soft skills included gender awareness. This article analyses the interviews to explore the experience of gender for both men and women in the Polish military, and shows that there is an urgent need for the type of training in gender awareness that is part of GAP.

Keywords: peacekeeping, pre-deployment training, women, gender awareness, stereotypes

\section{Gender and Peacekeeping*}

From 1957-1989, only twenty uniformed women served as peacekeepers under the auspices of the United Nations. Today, out of 125,000 military, police and civilian personnel, 5,160 are women. Women are deployed in all $16 \mathrm{UN}$ peacekeeping missions. There are 3 all-female UN police units deployed around the world. $30 \%$ of civilian personnel are female, $10 \%$ of police are female, and $4 \%$ of military personnel are female. (ed. Joseph 2016, p. 1862) There is no equivalent precise data for the EU, but estimates are that it is similar to that of the UN figures.

The three decades since the Brahimi Report have seen a long series of UN resolutions to address the deficit of women at every level of the peace and security agenda (U.N. Doc. A/55/305, 2000). By 2017, it can be said, that "After a long process the international legal scaffolding related to gender is largely in place". (Theidon, Phenicie and Murray, 2011) However, there is continued and protracted conflict, high levels of violence against women, and a plateau has been reached in the numbers of women in military, police and civilian positions in peacekeeping missions. Clearly there is a persistent gap between legislation and enforcement.

Numerous surveys have confirmed that the presence of women improves the effectiveness of the armed forces, especially in the field of peacekeeping missions and in terms of civil-military cooperation. There is increasing evidence that noncombat missions are best served by a better gender mix, particularly in terms of interaction with local communities. (Groothedde 2013) Bridges and Horsfall point out that the peacekeeping missions that have been successful in the past are those which have had close to equal members of males and females participating. (Bridges and Horsfall 2009, p. 122) 
Growing female participation is critical to:

- Empowering women in the host community;

- Interviewing victims of Gender Based Violence (GBV);

- Mentoring female cadets at police and military academies;

- Reducing misconduct rates and unlawful behaviour of peacekeeping forces.

One of the reasons for the recurrence of conflict is the absence of women and gender from the conflict analysis, and design and implementation of peacebuilding interventions into those conflicts (United Nations Women 2012). Sandole and Staroste point out 3 sets of tools that can help:

- Women's experience;

- Women's knowledge;

- Women's skills (Sandole and Staroste 2015).

However, despite substantial measures on improving and incorporating gender awareness programmes, mainstreaming gender in peacekeeping and conflict prevention training in recent decades is challenging. For many organisations it is seen as a box-ticking exercise. Training in awareness of gender as affecting both men and women, as being about masculinities as well as femininities, and the practical and moral necessity of gender equality in militaries, and hence on peacekeeping missions, is in short supply. GAP aims to contribute to training in this area.

\section{The GAP Project}

The qualitative interviews with Polish peacekeeping personnel were conducted as part of Gaming for Peace (GAP), an EU Horizon 2020 Framework Programme for Research and Innovation project. GAP was launched in September 2016 and the length of the project is 30 months. The GAP partners come from six countries: Ireland, Northern Ireland, Bulgaria, Poland, Portugal and Finland and consist of academic partners, military and police. The main goal of GAP is to develop a curriculum in relevant 'soft skills' (cooperation, communication, gender and cultural awareness) for personnel from diverse organisations working in the field of conflict prevention, peacebuilding and peacekeeping operations. This curriculum is being embedded in a digital role-playing game which will be available in 2019 . 
The curriculum and game scenarios are devised from state of the art but also from end-user interviews, including Polish respondents. The goal is to get a realistic picture of what is needed and to deliver content that is relevant and contextually appropriate.

To this end, between January and April 2017, 168 interviews with peacekeepers in six European Countries were completed. During the interviews, information was elicited from participants on the influence of gender on their peacekeeping deployments. The main objective of the investigation was to expedite further identification of gaps in soft skills in current curricula resulting from gender issues, and facilitate the development of narrative, scenarios and characters for the game scenarios.

This article focuses on the data generated for gender awareness, and focuses specifically on the data from the Polish military interviewees. After explaining the methodology, the first section of the analysis gives a country-by-country overview of the results of the interviews in the overall GAP project as they pertain to gender. The second part compares the findings on gender between Finland, Ireland, Bulgaria and Poland. The third section focuses on interviews with Polish personnel. All sections show that gender awareness is a key soft skill for peacekeepers and that despite the positive benefits of having more female peacekeepers, not only is there a 'stalled revolution' in terms of getting more gender balanced peacekeeping missions, but there is also a persistence of stereotyped notions of gender. This is most notable among the Polish respondents.

\section{Methodology}

For peacekeeper interviews, research was centred upon a qualitative research method using a semi-structured interview approach. "Qualitative research implies recognition of processes that are not readily susceptible to measurement in terms of quantity, amount or frequency. Its emphasis is on capturing or obtaining an in-depth understanding of the interactional processes as manifested during a particular study" (Garner, Wagner and Kawulich 2009, p. 63). The interviews across all regions were performed within a semi-structured framework in order to ensure that the key gender themes were discussed whilst still retaining a degree 
of flexibility that allowed new ideas to surface. Six specific questions concerning gender were put to the interviewees. Due to the nature of qualitative research, not every question was asked in exactly the same way to each participant.

Interviews were analysed using a two-step approach, the first step aimed to understand themes arising from the interviews overall. This was then followed by a detailed, country-by-country analysis. Interviews were analysed using Nvivo software. Thematic analysis of data aimed at identification of the main themes, which summarise all the collected views. The stages in thematic analysis were:

1) Reading and annotating transcripts;

2) Theme identification;

3) Development of a coding scheme (based on the questions in the guide to the semi-structured interviews);

4) Coding the data and supporting it with extracts.

Some codes were of a narrative nature as they related particularly to a specific individual's story.

Results for each country are presented under the following subheadings:

- Overall attitudes towards gender;

- Influence of gender in the mission environment;

- Mission Atmosphere;

- Disrespect towards women;

- What would encourage more women to become peacekeepers?

- How is gender covered in training?

Qualitative interviews were chosen as: "Research methods in social science research are an essential part of any research project as they determine its success, validity and reliability. Stemming from an interest in thorough understanding of human behaviour, social scientists tend to use qualitative research aiming to accumulate a detailed account of human behaviour and beliefs within the contexts they occur in" (Alshenqeeti 2014).

The interviews were conducted by GAP consortium partners, in which extremely rich and varied data was collated. Since GAP is concerned with assessing 'detailed human behaviour' in peacekeeping and determining the validity and reliability of the research, a large and diverse sample from several nations participated in the research. 


\section{Overall Results for GAP}

As illustrated in the diagram below, most interviewees were deployed in a mixed environment.

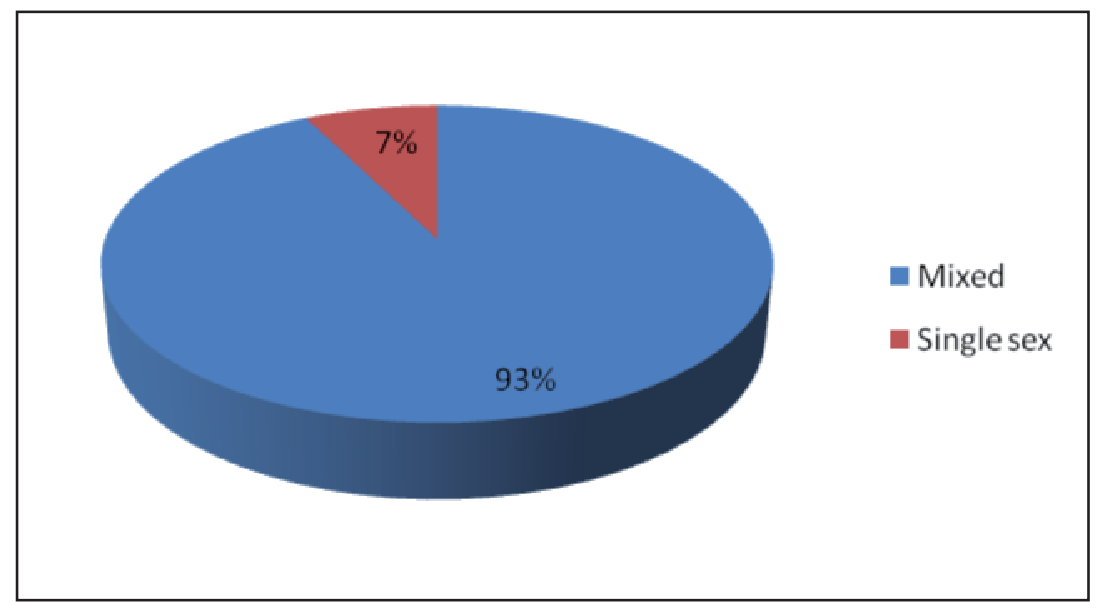

Fig. 1. Percentage of Interviewees deployed to mixed or single sex environments

Of those deployed to a mixed environment, the majority of interviewees stated that there were very few women. Women who were present on deployment were frequently described as occupying a limited number of roles, such as nurse, doctors or civilian or gender advisors.

\section{Influence of Gender}

Interviewees were asked if they could think of a time that they, or their colleagues, felt that gender made a difference. $83 \%$ of respondents gave examples of a time when gender made a difference. Occasions where the presence of female peacekeepers led to a positive outcome was discussed. Figure 2 shows the advantages of the presence of female peacekeepers as perceived by the interviewees. As may be seen, engagement with the local female population was the most commonly perceived benefit. This engagement could be in terms of 1) communication and intelligence gathering from local women; 2) being able to search local women; and 3) the 
perceived benefits of having a female officer to deal with female rape and human trafficking victims.

The second most popular perceived benefit of female peacekeepers may be summarised as 'positive reactions to women by locals.' This is the notion that local populations found a female peacekeeper less intimidating and were more inclined to be friendly and cooperative towards a female peacekeeper.

The final benefit was the notion of a different demeanour that women bring to a mission, this was described in terms of women being 'better' with children, and 'naturally friendlier' and 'chattier' with local populations.

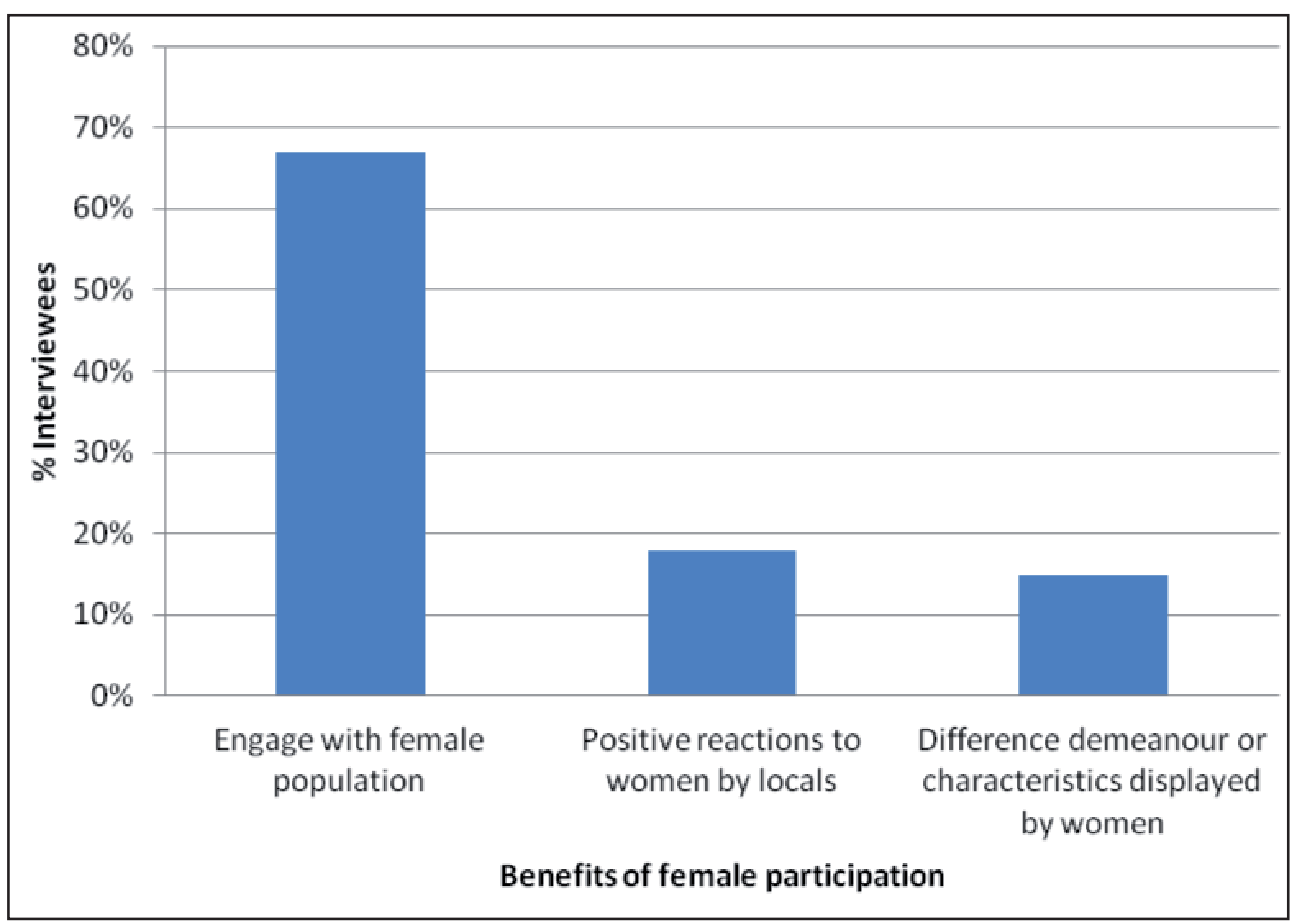

Fig. 2. Perceived benefits of the presence of female peacekeepers

\section{Disrespect towards female peacekeepers and local women}

Overall, a slight majority of respondents who answered this question, stated that they did witness incidents of disrespect towards female peacekeepers or local women, see figure 3 : 


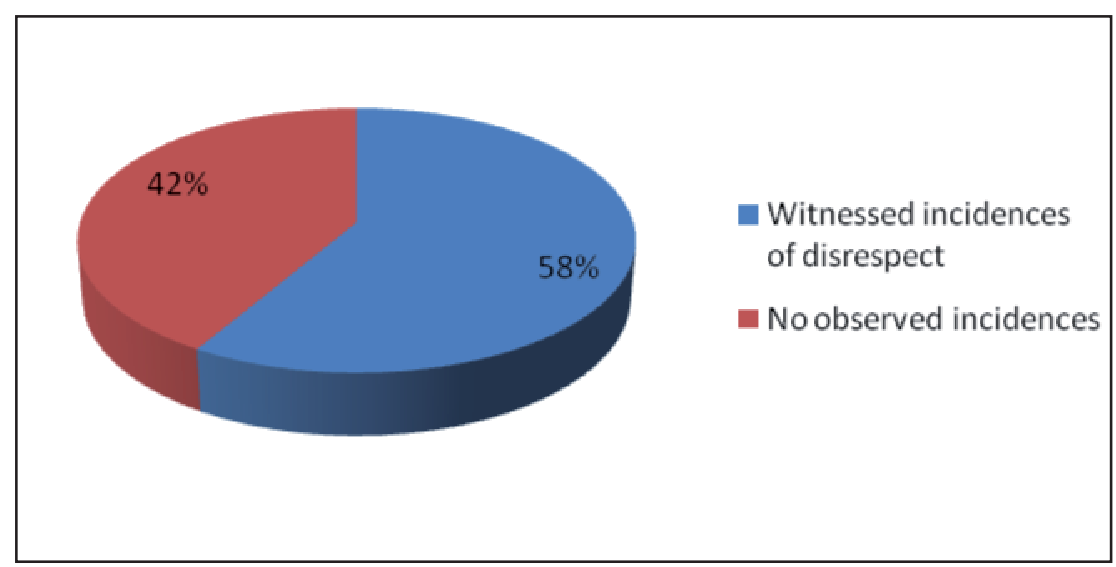

Fig. 3. Proportion of interviewees who witness disrespect of female peacekeepers and local women

Answers to the question about incidents of disrespect towards female peacekeepers or local women elicited three main responses 1) no observed incidences; 2) disrespect toward female peacekeepers both from the local community and from other peacekeepers; and 3) disrespect to local women both from peacekeepers and the local community.

\section{What would encourage more women to volunteer for peacekeeping missions?}

Figure 4 shows a word cloud, generated from running a word frequency analysis on the answers to the question as to what would encourage more women to volunteer for peacekeeping missions. A word frequency analysis was generated for the 50 most frequently mentioned words that were four letters and over. Words such as 'Peacekeeping and 'encourage' that were part of the question and generic words such as 'also' were removed. The word cloud shows the most frequently mentioned words in the largest font. As can be seen, the words 'family', 'children' and 'kids' feature largely. The word 'changes' is the most frequently spoken word.

On further analysis of the interview data, the word 'family' is spoken in reference to peacekeeping as time away from family, wanting to have a family (e.g. have children), or the need for more family-friendly policies. Similarly with the word 
'children', reference is made both to peacekeeping as time away from children, and the trade-off between going on peacekeeping deployment and the desire to have children.

\section{officers home monts problem example good kids make girls time training make come away three applying even many means

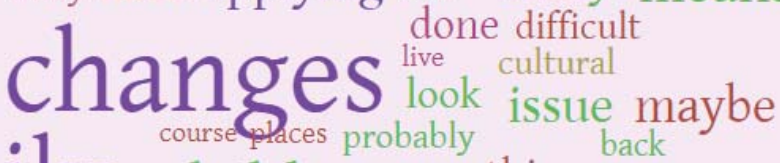 family children anyything positions taking need gender volunteer male work leave something}

Fig. 4. Word cloud to show frequency of the most spoken words in relation to what would increase female participant in peacekeeping missions

\section{Training on gender}

All Interviewees were asked if they received training on gender awareness before their deployment and whether they found this training useful.

Figure 5 shows the percentage of interviewees that stated they received gender training. 


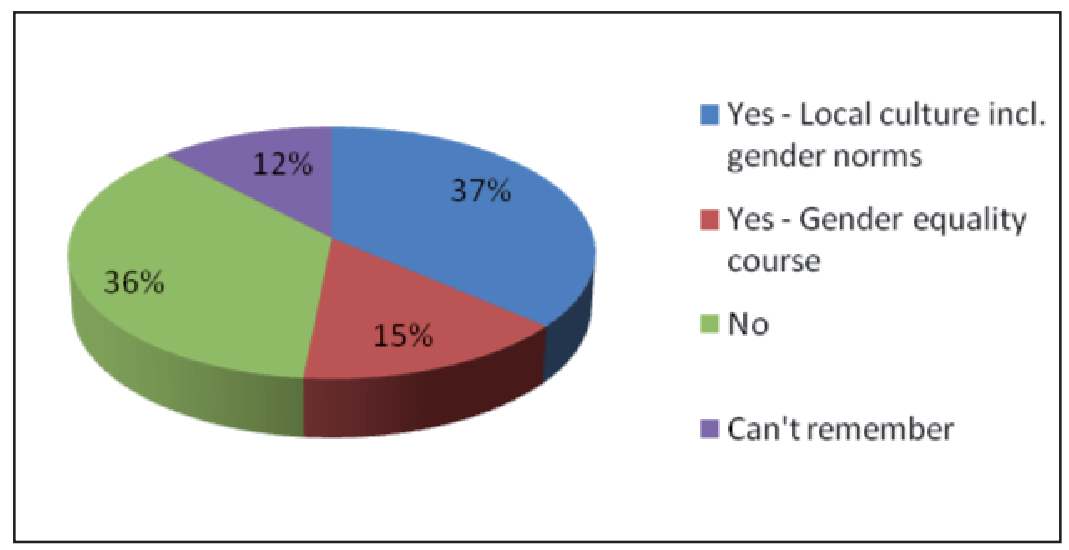

Fig. 5. Gender training received pre-deployment

As can be seen, the majority of interviewees stated they did receive some training in gender awareness. Of those that did receive training, this mostly consisted of training about gender norms in the local culture where they were to be deployed. While some interviewees described detailed briefings about local gender norms, others received only rudimentary instruction. A significant number of peacekeepers stated they did not receive any training in gender awareness, with a smaller proportion who couldn't remember either way.

\section{Finland, Ireland, Bulgaria and Poland}

Overall, there are significant regional differences in the way gender affects peacekeeping missions. Personnel from Finland receive the most gender awareness training and their society demonstrates a commitment to gender equality generally and specifically for our purposes in the military and civilian contributions to peacekeeping. However, the numbers and proportions of women to men on missions are still low, and there is continuing male dominance in how things are organised and where leadership is assigned. The male Finnish peacekeepers demonstrate a higher gender awareness of the impact of masculinity as well as femininity than male personnel from the other regions in the study. The overall understanding of gender awareness still focuses on women. 
The Irish military, Northern Irish police and Portuguese police have all reached a point where the presence of women is unquestioned, and the obvious benefits of having female personnel to meet the needs of accessing women in other societies are broadly recognised. There is also an unquestioned acceptance of the need for all personnel to have skills which would have traditionally been seen as 'feminine' - communication, cooperation, leadership, decision-making, cultural awareness, and there is recognition that women have a head start in having those skills, whether for reasons of nature or nurture. Gender issues arise in the response they have to the environment they find themselves working in - often in societies where there are very conservative ideas about male and female roles. There is an acceptance, more amongst the men than the women personnel that the women peacekeepers must abide by the local cultural norms, even if this means they are prevented from executing their duties fully, including that of leadership, as the local men would not accept it. Female personnel go along with this for the most part but some object strongly and feel that their right to do their job is being sacrificed to a type of cultural relativism.

Poland, Ukraine and Bulgaria accept the fact that women are now part of the landscape of military and police organisations and peacekeeping missions. Stereotypes persist of women, and are held by both men and women, creating challenges for female military personnel. There is a fairly rigid idea of what it is to be a soldier and it comprises qualities and skills traditionally associated with masculinity. If a woman can meet these standards she is accepted as a soldier but it is not seen as 'natural' for women to have these qualities. At the same time, there is a growing recognition that there are skills outside the 'male' skill set which are useful on peacekeeping missions. But there is confusion about how to square this with the male military model that still dominates.

There is a clear need for gender awareness, allied with cultural competency, to be part of training for peacekeeping personnel. Such training would provide men and women with the ability to recognise, appreciate and foster in themselves the qualities that are necessary for awareness of how gender roles are different in different societies, including how it shapes agency and power relationships, and an awareness of one's own socialised and socially shaped gender identity makes effective engagement in peacekeeping missions much more likely. 


\section{Finding from Polish interviews}

In general, respondents recounted that having women on missions made for a "nicer atmosphere" in the working environment. Women were seen as enablers of contact with local women, in particular in very conservative cultures. It was felt that local women can benefit from, for instance, medical services provided by the foreign component that otherwise could not be delivered. Women increased the problem-solving and conflict resolution capacities of the deployment. However, stereotyped notions of masculine and feminine behaviour persists, with negative consequences for the overall culture of the military and peacekeeping, as it does not make for an inclusive welcoming environment for both genders. Women are a relatively new phenomenon in the army, and are perceived as creating "hassle". Mixed units are seen as difficult to maintain discipline in, logistics and lodging is an issue and women are believed to require more time to adapt to the mission environment and not be "emotionally withstanding". It is perceived that women receive "special treatment", more is forgiven, which frustrates male colleagues.

\section{Gender and Training}

There is no specific gender training in the Polish Armed Forces, apart from antidiscrimination measures. In pre-deployment cultural training of personnel, some culturally relevant gender awareness is included. Personnel are advised about contact with local women in a different culture of the area of operation, and not only in Muslim cultures; specifically, they are told to: "pretend they (women) do not exist." Contact with local women is considered as troublesome.

"We just received information on women living in those areas." (Wojtek). "Something in the subject matter of local culture plus some political like gender" (Mariusz). Some respondents did not recollect any gender related training at all. "In general, we did not discuss such subjects. I do not remember anything like that" (Krzysztof). Despite the obvious lack of institutional gender awareness training, the respondents didn't feel it was something important that should be addressed more. "I do not know; I cannot think of anything. It is all proved in the field; you learn and adapt there" (Wojtek). 


\section{Persistent Stereotypes}

The majority of Polish interviewees were deployed to mix gender environments. A minority stated they were deployed in all male units. The attitude towards women in military varied amongst the respondents. They definitely found females useful in some situations, but still felt that there are areas on missions that should be restricted for men. Stereotyped notions about what is appropriate for men and women persist: "In specific cases, like a field hospital, I cannot imagine that there are no women there - they just must be there... First of all, in health care but also in communications and such areas as administration or logistics. I cannot imagine women serving in a transport company while driving a car or in a unit of bombers." (Wojtek)

Despite militaries struggling to recruit high standard personnel, with an emphasis on technology, several respondents from the Polish military put forward arguments against women in the military on the basis of physical strength: "But the woman is weaker physically, and I know for example that a woman will not pull me off the field with one hand and the other shoot, for example." (Robert)

Paternalistic masculinities are also evident amongst Polish respondents, expressed as the need to protect women: "I noticed that the man during the threat focused more on the woman. He wanted to protect her instinctively than to do the job she was supposed to perform, and the sight of the wounded woman was much more traumatic than the wounded colleague." (Robert)

Stereotypes persist among female interviewees also. One noticed a difference between American and Polish soldiers "letting women go first through door is normal in Poland. But for them, it does not matter whether it is a woman, a man, yes? So yes, there were differences like that. Also, men wouldn't help women, there was for example a little woman walking, she was carrying a big suitcase, or some kind of ammo box, where in our consciousness it was a little bit strange for women to carry that heavy stuff.' (Julita)

Despite what some men think about women lacking mental stamina for the missions, there is evidence that sometimes they have better ways of dealing with stress, as they are more open and ready to share their problems and it is socially acceptable for them to show emotion. The dominant model of masculinity 
makes it difficult for male soldiers to acknowledge and express their emotions constructively. As one of the female respondents explained: "And it turned out that as a woman it was easier to cope with stress, because I could stomp my foot, I could cry or talk with someone. Women are allowed to do that, men not really; they usually keep the stress in themselves. And sometimes it was also that one of your colleagues came: listen, I cannot do anything now because something is going on at home. So I would hug him and it did not mean anything improper, it was just comforting a teammate. The relations are different that in the civilian world, they have to move to another level." (Julita)

Polish cultural expectations of what women should be like and behave (submissive, dependent femininity) did influence the perception of females by male soldiers. Male soldiers struggled to deal with the more inclusive hiring now being aimed for by the Polish Armed Forces. The new order and resulting roles brought on them by the army creates an "unnatural situation" and functioning in such circumstances is perceived as difficult by the male personnel.

Exposure to other countries and differing gender norms demonstrates that there are different ways of being masculine and feminine for both genders, but it is not always taken as something relevant for Polish military personnel. For instance, respondents talked about how the female American military personnel were considered more professional, and they saw this as even to an extreme women carrying heavy loads themselves and refusing any help were looked up to. (Klemens) However, that was attributed to a different perception of femininity and gender equality in American society. Polish female personnel, in particular the civilian employees, were looked at as needing protection, unprofessional, sometimes as being in a given position only thanks to connections. (Wiesław) The female Polish personnel also exhibited these stereotypes: "I met with the situation that the Polish soldier tried to help a woman from a different quota [nation]. And she says, 'No, this is my job. It is also a show of self-respect. They pay me for it and I will do it by myself, I do not need anyone's help. "And in our place, a woman that was quite offended that time when she was forced to carry something, move something and nobody help her." (Klemens) 


\section{Disrespect towards women}

Polish personnel, when asked about observed incidences of disrespect towards female peacekeepers, responded with either 1) interviewees stating they had not witnessed anything of this nature; or 2) interviewees themselves casting aspersions on the ability of female peacekeepers.

Amongst those who held negative views about female abilities of peacekeepers, there was a view that Polish women were not willing to take on hard physical labour, and expected to be given an easier time in this respect. Women who were naturally fit for service in all positions were seen as a rare exception. In the words of one of the Polish respondents: "If, for example, 100 men graduate from an officer school, it is the outstanding $20-30 \%$, another $50 \%$ that are suitable, $10-15 \%$ bearable, and 5-10\% absolutely not fit for service. For women, out of the 100, one will be suitable, maybe two. Most of the rest are not suitable."(Goliad)

Moreover, all things feminine were considered not serious, and frivolous. Women in missions were seen as completely unprepared and out of place, unless with time they proved their professionalism, but this demanded getting rid of any feminine attributes.

\section{Changes that would encourage women to volunteer for peacekeeping missions}

The interviews indicate that stereotyped ideas about male and female roles and masculinities and femininities are a major barrier to women and men participating equally in the military and on peacekeeping missions. This is the primary issue which needs to be addressed. Opposition based on familial roles was also seen as a factor, but was raised as an issue for the men also. Polish respondents gave the view that the long separation influences women more negatively than men in the opinion of the interviewees, due to separation from children, and their partner leaving is more common. However, some respondents believed that, psychologically speaking, women were more likely to endure separation from their families, and it was men who could not cope; there have been cases where a man was unable to withstand that extreme separation and fell into neurosis for this reason. 


\section{Conclusions}

Gender mainstreaming produced an increase in the proportion of female military personnel in peacekeeping missions. However, this has plateaued at about 4\% in contemporary peacekeeping missions. As is evident from the data collected for GAP, this is partly because of the persistence of stereotyped notions about what is appropriate male or female behaviour, and about narrow definitions of masculinity and femininity. These ideas help create an atmosphere where it is difficult for female peacekeepers to be allowed to do their job, and where the culture is one that is not welcoming for anyone who is not a specific type of male. Gender awareness training would go some way to raising these issues and to get male and female military personnel to reflect on the impact of gender both in defining their ideas about who a peacekeeper is, and in questioning the limiting of what specific genders are allowed to feel and do. Training that encourages a comparative perspective, to help raise awareness that there is no one 'natural' way of being male or female or masculine or feminine, is particularly valuable.

\section{References}

Joseph, P. (ed.), 2016. The SAGE Encyclopedia of War: Social Science Perspectives. [online] Available from: https://www.iss.europa.eu/sites/default/files/EUISSFiles/ Alert_3_Gender_0.pdf [Accessed 20 Apr 2018].

The Panel on United Nations Peace Operations, chaired by Lakhdar Brahimi, reported to the U.N. Secretary-General on 17 August 2000: U.N. Doc. A/55/305. [online] Available from: http://www.un.org/documents/ga/docs/55/a55305.pdf [Accessed 20 Apr 2018].

Theidon, K. and Phenicie. K. with Murray, E., 2011. Gender, conflict, and peacebuilding state of the field and lessons learned. USIP. [online] Available from: http://www.usip. org/sites/default/files/Gender\%20conflict\%20and\%20peacebuilding.pdf [Accessed 22 Feb 2017].

Groothedde, S., 2013. Gender makes sense: A way to improve your mission. Civil-Military Cooperation Centre of Excellence (CCOE). [online] Available from: http://www.cimiccoe.org/wp-content/uploads/2014/06/Gender-Makes-Sense.pdf [Accessed 22 Feb 2017].

UN DPKO/DFS 2010. Integrating a gender perspective into the work of the United Nations military in peacekeeping operations[online] Available from: http://www.un.org/en/ 
peacekeeping/documents/dpko_dfs_gender_military_perspective.pdf [Accessed 22 Feb 2017].

United Nations General Assembly 2005. A comprehensive strategy to eliminate future sexual exploitation and abuse in United Nations peacekeeping operations. [online] Available from: https://cdu.unlb.org/Portals/0/Documents/KeyDoc5.pdf [Accessed 22 Feb 2017].

Bridgesd D., and Horsfall D., 2009. Increasing Operational Effectiveness in UN Peacekeeping. Toward a Gender-Balanced Force, Armed Forces \& Society, 36(1), 120-130.

UN Women Sourcebook on Women, Peace and Security 2012, p. 120 [online] Available from:http://www.unwomen.org/en/digital-library/publications/2012/10/un-womensourcebook-on-women-peace-and-security [Accessed 20 Apr 2018].

Sandole S., and Staroste I., 2015. Making the Case for Systemic, Gender-Based Analysis in Sustainable Peace Building. Conflict Resolution Quarterly, 33(2), 119-147.

Garner M., Wagner C. and Kawulich B., 2009. Teaching Research Methods in the Social Sciences. Farnham: Ashgate Publishing.

Alshenqeeti, H., 2014. Interviewing as a Data Collection Method; A Critical Review. English Linguistics Research, 3(1). 